\title{
Assessment of body composition of Sri Lankan Australian children using ethnic specific equations
}

\author{
V.P. Wickramasinghe ${ }^{1,2^{*}}$, G.J. Cleghorn ${ }^{2}$ and P.S.W. Davies ${ }^{2}$ \\ ${ }^{1}$ Department of Paediatrics, Faculty of Medicine, University of Colombo, Kynsey Road, Colombo 08. \\ ${ }^{2}$ Children's Nutrition Research Centre, Department of Paediatrics and Child Health, University of Queensland, Australia
}

\begin{abstract}
Since ethnic differences exist in body composition, assessment methods need to be validated prior to use in different populations. This study attempts to validate the use of Sri Lankan based body composition assessment tools on a group of 5 - 15 year old Australian children of Sri Lankan origin. The study was conducted at the Body Composition Laboratory of the Children's Nutrition Research Centre at the Royal Children's Hospital, Brisbane, Australia.
\end{abstract}

Height $(\mathrm{Ht})$, weight $(\mathrm{Wt})$, segmental length (L and skinfold thickness (SFT) were measured. The whole body and segmental bio impedance analysis (BIA) were also measured. The body composition determined by the deuterium dilution technique (criterion method) was compared with the assessments done using prediction equations developed on Sri Lankan children. 27 boys and 15 girls were studied. All predictions of body composition parameters, except percentage fat mass (FM) assessed by the SFT-FM equation in girls gave statistically significant correlations with the criterion method. They had a low mean bias and most were not influenced by the measured parameter. Although living in a different socioeconomic state, the equations developed on children of the same ethnic background gives a better predictive value of body composition. This highlights the ethnic influence on body composition.

Keywords: Anthropometry, bioelectrical impedance, body composition, ethnic specific equation, skin fold thickness, Sri Lankan Australian children.

\section{INTRODUCTION}

Anthropometry has been used to assess the nutritional status of individuals for many years. However with the deep understanding of the origin of many diseases and its relationship to body composition, assessment of body composition in clinical practice gained popularity over the last few decades. Detailed assessment of body composition for research was made using multicompartment body composition models with the use of sophisticated equipment. This needed expensive equipment and trained personnel, which is a drawback for day-to-day clinical and epidemiological use. Furthermore they may not be user friendly, diminishing the necessary cooperation from children. The two compartment body composition model, which divides body into fat mass (FM) and fat free mass (FFM), is a simple model that would provide information on body composition sufficient for use in day-to-day clinical practice and epidemiological studies (McCarthy et al., 2006). Bio impedance analysis (BIA), skin fold thickness (SFT) and anthropometry are some other simpler methods that can be used. These body composition assessment techniques use indirect methods based on statistical models. Ethnic variation is an identified fact that affects the assessment of body composition (Deurenberg et al., 2002) as well as BMI based obesity cutoff values (Wickramasinghe et al., 2009). As ethnicity influences body composition, the best assessment by these indirect methods could be achieved by using prediction equations developed on the same or genetically closer populations (Wickramasinghe et al., 2005a). In the absence of such equations, those which are available in the literature could be used after validation (Wickramasinghe et al., 2005b). Apart from ethnicity, the socioeconomic environment people live in, also affects body composition. Deurenberg and co-workers (1998) in a meta-analysis showed that White Caucasians living in Europe has a higher percentage of fat for any given BMI, compared to their Caucasian counterparts living in North America. The body composition of Sri Lankan Australian children is quite different from their Caucasian counterparts and when assessed using 
some of the assessment methods available in the literature, there had been higher bias (Wickramasinghe et al., 2005a). Furthermore it has been shown that using the existing BMI cutoff values to diagnose obesity in Sri Lankan Australian children showed poor sensitivity, thus underestimating the problem (Wickramasinghe et al., 2005c). Therefore as highlighted in the literature, it is most prudent to use methodologies developed on the specific ethnic group. In the present study we attempt to assess the body composition of Australian children of Sri Lankan origin using prediction equations developed on Sri Lankan children (vide infra). The body composition of Australian children of Sri Lankan origin has not been studied earlier using these new prediction equations. Results of this study will enable the evaluation of the usefulness of ethnic specific equations on the assessment of body composition of populations living away from their native land in different socioeconomic environments.

\section{METHODS AND MATERIALS}

\section{Subjects}

Five to 15-year-old healthy Sri Lankan migrant children $(\mathrm{n}=42)$ living in Brisbane, Australia for more than 2 years and with no illness or special physical training were recruited through community centres in Brisbane. The study was conducted at the Body Composition Laboratory of Children's Nutrition Research Centre at the Royal Children's Hospital, Brisbane after receiving ethical clearance from the Medical Research Ethics Committee of the University of Queensland and the Ethics Committee of Royal Children's Hospital, Brisbane.

Total body water (TBW) was measured using isotope dilution method. The procedure began with the subject emptying his/her bladder and collecting a sample of urine $(10 \mathrm{~mL})$ into a screw-capped bottle to determine basal $\mathrm{D}_{2} \mathrm{O}$ levels. A $10 \% \mathrm{D}_{2} \mathrm{O}$ dose of $0.5 \mathrm{~g} / \mathrm{kg}$ body weight was given with the dose being measured to $0.01 \mathrm{~g}$ (Bell et al., 1998). A second sample of urine $(10 \mathrm{~mL})$ was collected 4 - 6 hrs later. $\mathrm{D}_{2} \mathrm{O}$ in the collected urine samples was measured using isotope ratio mass spectrometry (Hydra, Europe Scientific Crewe, UK) at the Children's Nutrition Research Centre, University of Queensland, Australia. From TBW, FFM and hence FM was calculated using age and sex specific water content of FFM (Lohman, 1989; Wickramasinghe et al., 2008a).

Height, weight and skin fold thickness was measured using standard techniques (Wickramasinghe et al., 2008b). BIA (resistance) was measured with a single frequency $(50 \mathrm{kHz})$ electric current of $800 \mu \mathrm{A}$ with 4 surface-electrodes (Bodystat instrument ${ }^{\circledR}$, Bodystat Ltd., Isle of Man, British Isles) as follows. The subject lay supine on a bed with a non-conductive surface. Hands were kept slightly abducted to prevent touching the trunk. Legs were abducted to place a minimum of $20 \mathrm{~cm}$ between the two medial malleoli to avoid the thighs touching each other (Baumgartner, 1996). For the whole body impedance measurement, the surface electrodes for the source current (discharging electrodes) were placed at the third metacarpo-phalangeal joint in the left hand and third metatarso-phalangeal joint of the left foot. The sensing electrodes were kept midway between the styloid processors and malleoli of the left wrist and left ankle, respectively. A minimum distance of $5 \mathrm{~cm}$ was maintained between the source and sensing electrodes to avoid any interference. If the natural length was $<5 \mathrm{~cm}$, the sensing electrode was moved till the desired distance was achieved (Baumgartner, 1996). Conduction gel coated disposable surface electrodes $\left(5 \mathrm{~cm}^{2}\right.$, Kendall QTrace $5400 \AA$, Ludlow Company Ltd., USA) were used and connected to the BIA machine via crocodile clips.

In the segmental BIA measurement, source electrodes were placed as for the whole body impedance measurement. The sensing electrodes for upper limb segment were placed at left wrist midway between the styloid processors and at left acromion. Impedance of lower limb was measured by placing the sensing electrodes midway between the maleoli of the left ankle joint and at the left anterior superior iliac spine. Impedance of the trunk was measured by placing the sensing electrodes at left acromion and left anterior superior iliac spine. The distance between each segmental electrode was measured to the closest $0.1 \mathrm{~cm}$, which was considered to be the length of the segment.

\section{Prediction of body composition}

Body composition was assessed using different prediction equations developed on Sri Lankan children (Sex code; male $=1$ and female $=0$; Age in years; II = impedance index $\left(\mathrm{cm}^{2} \Omega^{-1}\right)$ was calculated by height ${ }^{2}\left(\mathrm{~cm}^{2}\right) /$ impedance $(\Omega)$ or segment length ${ }^{2}\left(\mathrm{~cm}^{2}\right) /$ impedance $\left.(\Omega)\right)$.

Whole body BIA (Wickramasinghe et al., 2008a)

$\mathrm{TBW}=0.41 \mathrm{II}_{\text {whole body }}+0.17$ Weight +1.1 Sex Code +0.44

$\mathrm{FFM}=0.56 \mathrm{II}_{\text {whole body }}+0.22$ Weight +1.6 Sex Code -0.22 
Skin fold thickness equation (Wickramasinghe et al., 2008b)

$$
\begin{aligned}
\mathrm{FM}= & (0.68 \times \text { Age })+(0.246 \times \text { SFT-Tri })+(0.383 \times \text { SFT SS }) \\
& -(1.61 \times \text { Sex Code })-3.45 \\
\% \mathrm{FM}= & (-0.28 \times \text { Age })+(0.49 \times \text { SFT-Tri })+(0.34 \times \text { SFT } \\
& \text { SS })-(7.97 \times \text { Sex Code })+26.8
\end{aligned}
$$

Height weight equation (Wickramasinghe et al., 2010)

TBW $=0.13$ Height +0.27 Weight +1.82 Sex Code -10.35

Segmental BIA (Wickramasinghe et al., 2012)

$\mathrm{TBW}=\left(2.1 \times \mathrm{II}_{\text {Upper limb }}\right)+\left(0.19 \times \mathrm{II}_{\text {Trunk }}\right)-\left(0.089 \times \mathrm{L}_{\text {Upper Limb }}\right)$

$+(0.17 \times$ Age $)+(0.82 \times$ Sex Code $)+4.12$

$\mathrm{TBW}=\left(0.62 \times \mathrm{II}_{\text {Lower limb }}\right)+\left(0.25 \times \mathrm{II}_{\text {Trunk }}\right)+\left(0.041 \times \mathrm{L}_{\text {Lower Limb }}\right)$

$-(0.13 \times$ Age $)+(1.3 \times$ Sex Code $)-0.37$

FFM $=\left(2.8 \times \mathrm{II}_{\text {Upper limb }}\right)+\left(0.24 \times \mathrm{II}_{\text {Trunk }}\right)-\left(0.13 \times \mathrm{L}_{\text {Upper Limb }}\right)$

$+(0.31 \times$ Age $)+(1.3 \times$ Sex Code $)+4.9$

FFM $=\left(0.84 \times \mathrm{II}_{\text {Lower limb }}\right)+\left(0.33 \times \mathrm{II}_{\text {Trunk }}\right)+(0.037 \times$

$\left.\mathrm{L}_{\text {Lower Limb }}\right)-(0.0581 \times$ Age $)+(1.9 \times$ Sex Code $)-0.84$

Once the body composition was assessed by each equation (primary body composition parameter), secondarily FM was assessed based on the two compartment body composition model, unless the equation assessed FM as its primary outcome. Percentage FM is FM expressed as percentage of body weight.

\section{Statistics}

The distribution of demographic and body composition parameters were described using descriptive statistics (mean and standard deviation). Body composition parameters assessed by the criterion method as well as the prediction equations were compared using one way analysis of variance (ANOVA) of Bonferroni multiple comparison procedure.

The method described by Bland and Altman (1986) was used to identify the agreement between the values obtained by prediction equation and criterion method. Analysis were done using NCSS 2000 (Hintze JL, Kayswille, Utah, USA) for windows statistical computer packages.

\section{RESULTS}

Out of the fifteen girls and twenty-seven boys studied, twenty-five (60\%) children (16 boys and 9 girls) were born in Australia. The mean duration of residence of the other children was 6.8 years (range $3.1-10.2$ years). Table 1 shows the demographic and body composition characteristics of the study population according to sex. The two groups were similar apart from the girls having significantly higher level of FM and \% FM.

Table 1: Demographic characteristics and body composition parameters of Sri Lankan Australian children by gender.

\begin{tabular}{lcc}
\hline & Male & Female \\
\hline $\mathrm{N}$ & 27 & 15 \\
Age (years) & $9.1 \pm 3.5$ & $9.6 \pm 2.6$ \\
Weight $(\mathrm{kg})$ & $29.0 \pm 9.5$ & $34.1 \pm 14.0$ \\
Height $(\mathrm{cm})$ & $131.8 \pm 14.8$ & $135.5 \pm 16.2$ \\
BMI $\left(\mathrm{kg} / \mathrm{m}^{2}\right)$ & $16.2 \pm 2.7$ & $17.7 \pm 2.6$ \\
BMI-Z & $-034 \pm 1.58$ & $0.10 \pm 1.15$ \\
TBW $(\mathrm{L})$ & $16.5 \pm 4.6$ & $18.4 \pm 6.8$ \\
FM $(\mathrm{kg})$ & $6.9 \pm 4.6$ & $10.2 \pm 5.5^{*}$ \\
$\%$ FM & $22.9 \pm 8.7$ & $29.0 \pm 6.0^{* *}$ \\
FFM $(\mathrm{kg})$ & $21.8 \pm 6.6$ & $23.9 \pm 9.1$ \\
FMI $\left(\mathrm{kg} / \mathrm{m}^{2}\right)$ & $3.9 \pm 2.1$ & $5.3 \pm 1.8$ \\
Impedance $(\Omega)$ & $759 \pm 100.6$ & $782 \pm 92$ \\
Impedance index $\left(\mathrm{cm}^{2} \Omega^{-1}\right)$ & $23.5 \pm 7.1$ & $23.5 \pm 7.1$ \\
\hline
\end{tabular}

${ }^{*} 0.001<\mathrm{p}<0.01,{ }^{* * *} \mathrm{p}<0.001$

BMI - body mass index; BMI-Z - body mass index Z-scores; TBW - total body water; FM - fat mass; FFM - fat free mass ; FMI - fat mass index

Table 2 shows the primary body composition values (TBW, FFM, FM or \% FM) predicted by each equation, the $\mathrm{FM}$ and \% FM derived from each prediction equation, and the correlation between the predicted parameter (by different equations) and the value obtained by the criterion method. Most showed statistically significant high correlation coefficients. FM assessed by different methods gave values quite closer to the criterion assessment and the differences observed were not statistically significant. Although \% FM showed a similar pattern of distribution, assessment made by the whole body BIA prediction equation for FFM gave a significantly higher \% FM than the assessment made by the criterion method. Except for \% FM assessment in girls using SFT-FM equation $(r=0.41, p=0.13)$, all had statistically significant high correlations with the criterion assessment. 


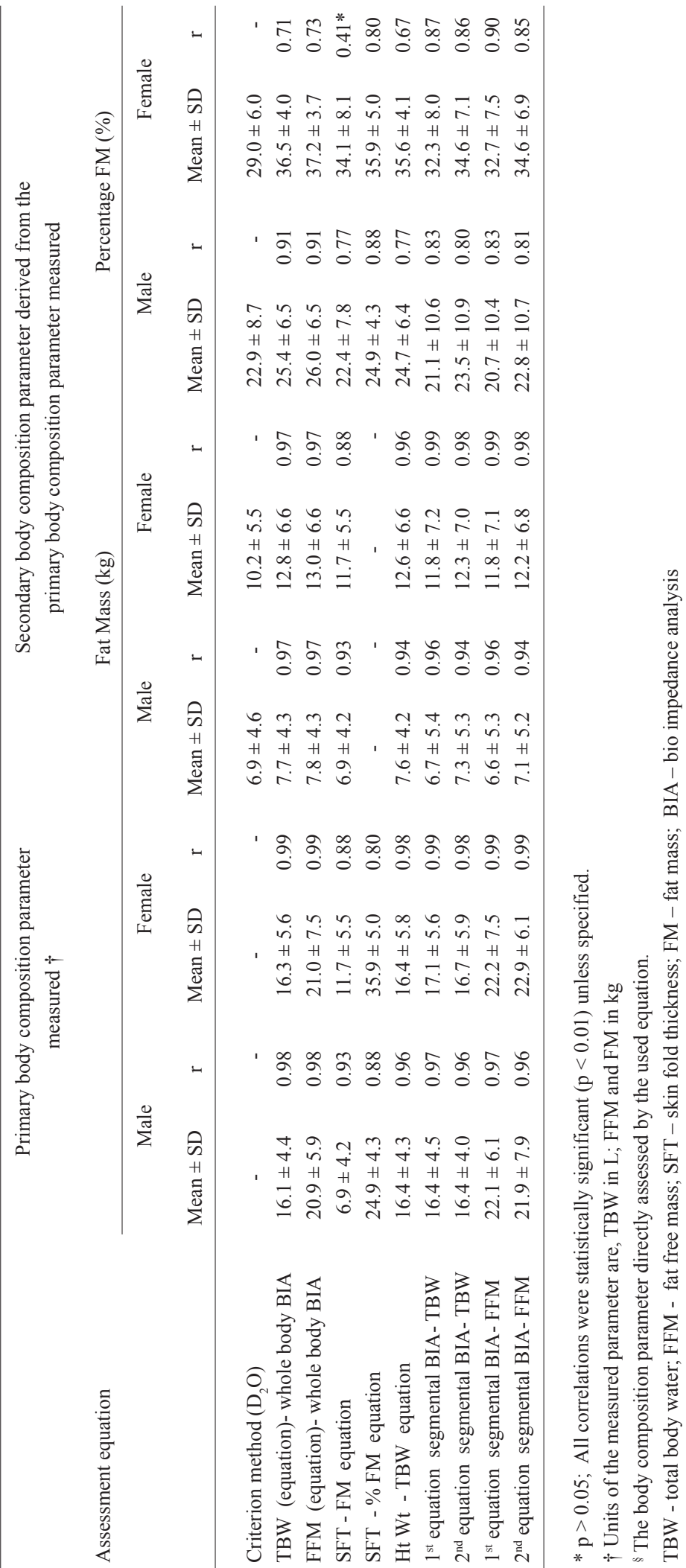


The bias in the assessment of body composition by each method is shown in Table 3 . All the equations used to assess TBW gave a bias under $0.5 \mathrm{~L}$ in boys and less than $2.1 \mathrm{~L}$ in girls. In the assessment of FFM, all equations except whole body BIA for FFM equation $(2.7 \mathrm{~kg})$ in girls gave a mean bias under $2.0 \mathrm{~kg}$. Similar patterns were observed in the assessment of FM and \% FM as well. The assessment in females was always weaker than in males. Table 3 shows the limits of agreement (LOA) (95\% CI interval) for the mean bias of each assessment. Most had narrow LOA for the assessment of FM (under 2 $\mathrm{kg}$ ) and \% FM (under $5 \%$ ) in both gender groups.

The correlation between the bias (predicted - actual) and the mean of the body composition parameter assessed by the prediction equation and criterion method [(predicted + actual)/2] was assessed (Table 4). The existence of a significant correlation (un-shaded values) denotes that extremes of measure influence the bias. That is the method, which either over or under estimates at extremes of values. This relationship could be demonstrated pictorially by using a Bland Altman plot (not shown). The values with statistically not significant relationships are given in the shaded background in Table 4. For the prediction of \% FM most of the equations in both gender groups had a bias that was not influenced by extremes of values.

One way ANOVA results showed that TBW assessed by the four equations agreed with the criterion method in both gender groups. Equations that predicted FFM (3 equations) and FM (1 equation) as the primary measure agreed with the criterion method. Except for the assessment of \% FM in girls by FFM equation whole body BIA, all the other assessments of FM and \% FM by other equations agreed with the criterion evaluation as well as the values obtained by other techniques. This denotes that ethnic specific equations were able to predict body composition of Australian children of Sri Lankan origin with greater accuracy.

Table 3: Bias and limits of agreement for mean bias in the assessment of body composition (primary component, FM and \%FM) using different Sri Lankan equations on Sri Lankan Australian children by gender

\begin{tabular}{|c|c|c|c|c|c|c|}
\hline \multirow[t]{3}{*}{ Assessment equation } & \multirow{2}{*}{\multicolumn{2}{|c|}{$\begin{array}{l}\text { Primary body composition } \\
\text { parameter measured } \dagger \\
{[\mathrm{Mean} \pm \mathrm{SD}(95 \% \mathrm{CI})]}\end{array}$}} & \multicolumn{4}{|c|}{$\begin{array}{l}\text { Secondary body composition parameter derived from the } \\
\text { primary body composition parameter measured } \\
{[\text { Mean } \pm \mathrm{SD}(95 \% \mathrm{CI})]}\end{array}$} \\
\hline & & & \multicolumn{2}{|c|}{ Fat mass $(\mathrm{kg})$} & \multicolumn{2}{|c|}{ Percentage fat mass $(\%)$} \\
\hline & Male & Female & Male & Female & Male & Female \\
\hline TBW (equation)-whole body BIA & $\begin{array}{r}-0.42 \pm 0.85 \\
(0.10 \text { to } 0.74)\end{array}$ & $\begin{array}{c}-2.1 \pm 1.5 \\
(-1.32 \text { to } 2.85)\end{array}$ & $\begin{array}{c}0.54 \pm 1.1 \\
(0.95 \text { to } 0.13)\end{array}$ & $\begin{array}{c}2.7 \pm 2.0 \\
-1.69 \text { to } 3.70\end{array}$ & $\begin{array}{r}2.1 \pm 3.6 \\
(0.8 \text { to } 3.4)\end{array}$ & $\begin{array}{r}7.6 \pm 4.2 \\
(5.5 \text { to } 8.7)\end{array}$ \\
\hline FFM (equation)-whole body BIA & $\begin{array}{c}-0.54 \pm 1.1 \\
(-0.13 \text { to } 0.95)\end{array}$ & $\begin{array}{c}-2.7 \pm 2.0 \\
(-1.75 \text { to } 3.65)\end{array}$ & $\begin{array}{c}0.60 \pm 1.1 \\
(0.18 \text { to } 1.00)\end{array}$ & $\begin{array}{c}2.9 \pm 1.9 \\
2.00 \text { to } 3.80\end{array}$ & $\begin{array}{r}2.4 \pm 3.7 \\
(1.0 \text { to } 3.8)\end{array}$ & $\begin{array}{r}8.5 \pm 4.1 \\
\text { (6.4 to } 10.6)\end{array}$ \\
\hline SFT - FM equation & $\begin{array}{c}-0.3 \pm 1.8 \\
(0.37 \text { to } 0.98)\end{array}$ & $\begin{array}{c}1.5 \pm 2.7 \\
(-0.18 \text { to } 2.92)\end{array}$ & $\begin{array}{c}-0.3 \pm 1.8 \\
(-0.97 \text { to }-0.37)\end{array}$ & $\begin{array}{c}1.5 \pm 2.7 \\
(0.19 \text { to } 2.90)\end{array}$ & $\begin{array}{c}-1.1 \pm 5.5 \\
(-3.3 \text { to } 1.1)\end{array}$ & $\begin{array}{r}5.5 \pm 7.8 \\
(2.0 \text { to } 9.4)\end{array}$ \\
\hline SFT - \% FM equation & $\begin{array}{c}1.3 \pm 5.2 \\
(0.69 \text { to } 3.24)\end{array}$ & $\begin{array}{c}7.3 \pm 3.6 \\
(-5.48 \text { to } 9.12)\end{array}$ & - & - & $\begin{array}{r}1.3 \pm 5.2 \\
(-0.7 \text { to } 3.3)\end{array}$ & $\begin{array}{r}7.3 \pm 3.6 \\
(5.5 \text { to } 9.1)\end{array}$ \\
\hline Ht Wt - TBW equation & $\begin{array}{c}-0.24 \pm 1.3 \\
(0.26 \text { to } 0.74)\end{array}$ & $\begin{array}{c}-1.9 \pm 1.5 \\
(-1.12 \text { to } 2.67)\end{array}$ & $\begin{array}{c}0.31 \pm 1.7 \\
(-0.32 \text { to } 0.94)\end{array}$ & $\begin{array}{c}2.5 \pm 2.0 \\
(1.40 \text { to } 3.50)\end{array}$ & $\begin{array}{c}1.1 \pm 5.4 \\
(-0.9 \text { to } 3.1)\end{array}$ & $\begin{array}{r}7.2 \pm 4.4 \\
(5.0 \text { to } 9.4)\end{array}$ \\
\hline $1^{\text {st }}$ equation segmental BIA- TBW & $\begin{array}{c}0.41 \pm 1.2 \\
(0.04 \text { to } 0.86)\end{array}$ & $\begin{array}{c}-1.3 \pm 1.5 \\
(-0.51 \text { to } 2.01)\end{array}$ & $\begin{array}{c}0.53 \pm 1.5 \\
(-1.10 \text { to } 0.07)\end{array}$ & $\begin{array}{c}1.6 \pm 1.9 \\
(0.60 \text { to } 2.60)\end{array}$ & $\begin{array}{c}-2.5 \pm 5.9 \\
(-4.7 \text { to }-0.3)\end{array}$ & $\begin{array}{r}3.7 \pm 4.1 \\
(2.7 \text { to } 4.7)\end{array}$ \\
\hline $2^{\text {nd }}$ equation segmental BIA- TBW & $\begin{array}{c}-0.07 \pm 1.3 \\
(-6.45 \text { to } 7.47)\end{array}$ & $\begin{array}{c}-1.6 \pm 1.5 \\
(-0.90 \text { to } 2.37)\end{array}$ & $\begin{array}{c}0.09 \pm 1.7 \\
(-0.54 \text { to } 0.66)\end{array}$ & $\begin{array}{c}2.1 \pm 1.9 \\
(1.10 \text { to } 3.10)\end{array}$ & $\begin{array}{l}-0.11 \pm 6.5 \\
(-2.6 \text { to } 2.4)\end{array}$ & $\begin{array}{r}5.9 \pm 3.5 \\
(4.1 \text { to } 7.7)\end{array}$ \\
\hline $1^{\text {st }}$ equation segmental BIA- FFM & $\begin{array}{c}0.66 \pm 1.5 \\
(-0.07 \text { to } 1.26)\end{array}$ & $\begin{array}{c}-1.7 \pm 1.8 \\
\text { (-0.77 to } 2.57)\end{array}$ & $\begin{array}{c}0.70 \pm 1.5 \\
(-1.2 \text { to }-0.06)\end{array}$ & $\begin{array}{c}1.7 \pm 1.8 \\
\text { (0.70 to } 2.50)\end{array}$ & $\begin{array}{c}-2.8 \pm 5.9 \\
(-4.9 \text { to }-0.7)\end{array}$ & $\begin{array}{r}4.0 \pm 3.4 \\
\text { (2.3 to } 5.7)\end{array}$ \\
\hline $2^{\text {nd }}$ equation segmental BIA- FFM & $\begin{array}{c}0.16 \pm 1.7 \\
(0.50 \text { to } 0.81)\end{array}$ & $\begin{array}{c}-2.0 \pm 1.8 \\
(-1.14 \text { to } 2.87)\end{array}$ & $\begin{array}{c}-0.16 \pm 1.7 \\
(-0.80 \text { to } 0.49)\end{array}$ & $\begin{array}{c}2.0 \pm 1.7 \\
(1.10 \text { to } 2.90)\end{array}$ & $\begin{array}{c}-0.8 \pm 6.4 \\
(-3.2 \text { to } 1.6)\end{array}$ & $\begin{array}{r}5.9 \pm 3.7 \\
(4.0 \text { to } 7.8)\end{array}$ \\
\hline
\end{tabular}

$\dagger$ Units of the measured parameter are, TBW in L; FFM and FM in kg

TBW - total body water; FFM - fat free mass; SFT - skin fold thickness; FM - fat mass; BIA - bio impedance analysis 
Table 4: Correlation between bias (predicted - actual) and the mean of the body composition parameter assessed by the prediction equation and criterion method [(predicted + actual)/2] on Sri Lankan Australian children by gender

\begin{tabular}{|c|c|c|c|c|c|c|}
\hline \multirow[t]{2}{*}{ Assessment equation } & \multicolumn{2}{|c|}{$\begin{array}{c}\text { Primary body composition } \\
\text { parameter measured } \pm\end{array}$} & \multicolumn{2}{|c|}{ Fat mass (kg) } & \multicolumn{2}{|c|}{ Percentage fat mass } \\
\hline & Male & Female & Male & Female & Male & Female \\
\hline TBW equation - whole body BIA & $-0.18(0.35)$ & $-0.77(<0.01)$ & $-0.27(0.17)$ & $-0.60(0.01)$ & $-0.45(0.02)$ & $-0.11(0.69)$ \\
\hline FFM equation - whole body BIA & $-0.03(0.87)$ & $-0.72(<0.01)$ & $0.36(0.06)$ & $-0.54(0.03)$ & $0.49(0.01)$ & $-0.01(0.99)$ \\
\hline SFT - FM equation & $-0.29(0.14)$ & $-0.01(0.96)$ & - & - & $-0.13(0.53)$ & $0.31(0.25)$ \\
\hline SFT - \% FM equation & - & - & - & - & $-0.83(<0.01)$ & $-0.27(0.32)$ \\
\hline $\mathrm{Ht} \mathrm{Wt}$ - TBW equation & $-0.18(0.35)$ & $-0.67(<0.01)$ & $-0.35(0.07)$ & $0.51(0.05)$ & $-0.41(0.03)$ & $-0.44(0.09)$ \\
\hline $1^{\text {st }}$ equation segmental BIA- TBW & $-0.07(0.72)$ & $-0.83(<0.01)$ & $0.43(0.02)$ & $0.86(<0.01)$ & $0.37(0.06)$ & $0.51(0.04)$ \\
\hline $2^{\text {nd }}$ equation segmental BIA- TBW & $-0.01(0.97)$ & $-0.66(<0.01)$ & $0.32(0.10)$ & $0.76(<0.01)$ & $0.30(0.27)$ & $0.40(0.04)$ \\
\hline $1^{\text {st }}$ equation segmental BIA- FFM & $0.06(0.75)$ & $-0.79(<0.05)$ & $0.38(0.05)$ & $0.84(<0.01)$ & $0.35(0.10)$ & $0.46(0.08)$ \\
\hline $2^{\text {nd }}$ equation segmental BIA- FFM & $0.15(0.44)$ & $-0.54(<0.04)$ & $0.24(0.22)$ & $0.70(<0.01)$ & $0.37(0.05)$ & $0.27(0.33)$ \\
\hline
\end{tabular}

Non significant correlations are given in shaded background.

TBW - total body water; FFM - fat free mass; SFT - skin fold thickness; FM - fat mass; BIA - bio impedance analysis

\section{DISCUSSION}

Today the world is faced with a major epidemic of childhood obesity with an elevated risk among the South Asian populations developing insulin resistance. It further increases when they adopt a westernized lifestyle either in the native land or in the newly migrated country (Whincup et al., 2002). Management of childhood obesity is quite challenging. Diet restrictions and exercise programmes could help in reducing the weight of the body. However, reduction in weight could occur due to a reduction of FFM rather than FM. During growing years this could have long term adverse effects. This difference is not appreciated by simple weight or BMI measurement. Therefore FM reduction, which is the main objective in obesity management cannot be assessed successfully using the weight or BMI and direct assessment of FM is the best method. Accurate assessment of body composition in every individual is important. As body composition is affected by ethnic origin, it is necessary to identify suitable methods for body composition assessment in populations that have migrated to different parts of the world.

The body composition of this cohort was assessed using equations derived on white Caucasian populations and published earlier (Wickramasinghe et al., 2005a \& b). Most of the predicted body composition parameters did not agree with the criterion method and had significant bias in the assessment. The LOA for the assessment of $\%$ FM was very wide. In most of the situations the bias showed a statistically significant association with the mean of the body composition parameter assessed by the prediction equation and criterion method [(predicted + actual)/2]. This denotes that the bias is influenced by extremes of values. Compared to the previous study a significant feature observed in this study was that all primary parameters predicted by the equations were comparable to the values obtained by the criterion method. The mean bias was quite low and also the LOA was quite narrow for both primary parameter assessment as well as \% FM assessment (less than $5 \%$ ). These values were quite satisfactory for such indirect methods specially when compared with the results obtained by other equations derived on non-Sri Lankan populations (Wickramasinghe et al., 2005a).

The segmental BIA was used as an alternative to whole body BIA, as under certain circumstances it may not be possible to place electrodes (skin wounds, infections, limiting access due to interventions in hospital patients etc.) for whole body BIA assessment. However there are not many segmental BIA equations in the literature for comparison.

Our previous work clearly showed that although populations were living in western socio-economical environments, their body composition could not be assessed accurately by the equations validated on those populations (Wickramasinghe et al., 2005a). The present study shows that the use of ethnic specific equations provides more accurate data on body composition assessment. Predictions in boys were always stronger than in girls; however, the exact reason for this is not clear. Of the methods that we have evaluated, three used anthropometric measures to assess body 
composition. Height and weight measures can be done easily with minimum equipment and training, and the degree of reproducibility is high. The assessment of TBW and FM using height-weight based equations gave accurate estimates. SFT measurement can be done easily and it provided accurate estimates for FM as well as \% FM. However, the reproducibility is low specially in obese individuals. Considering the accuracy and cost effectiveness, anthropometry based body composition assessment techniques would be a good practical alternative for weight.

BIA has gained popularity in body composition assessment, mainly due to its simplicity and relatively inexpensive equipment. The accuracy provided by BIA based equations is quite high. Although we did not draw Bland-Altman plots, the relationship between the bias and mean \% FM assessed by the study method and the reference method did not show a significant relationship, and the LOA were narrow. This was quite different from the results obtained in the assessment of body composition using non-Asian derived equations available in the literature (Wickramasinghe et al., 2005a).

This study supports the notion that ethnicity determines the body composition to a greater extent. The use of prediction equations developed on groups of the same ethnic background gives satisfactory assessment. However, one may argue that even the hydration constants of FFM would depend on the ethnicity. It has been shown that the conversion of TBW to FFM does not have a biologically relevant difference in the hydration of FFM across different ethnic groups (Deurenberg \& Deurenberg-Yap, 2003). This is the first time these equations (developed on Sri Lankan children) were validated on an independent group, and the results have shown the importance of using ethnic specific equations in the assessment of body composition of children.

\section{CONCLUSION}

Although living in a different socioeconomic environment, ethnic specific body composition prediction equations were able to assess the body composition more accurately. Proper understanding of the body composition of people of different ethnic backgrounds living in a multiethnic population is important to use the most suitable assessment techniques. Although second generation migrant individuals have not lost their ethnic identity in body composition, it would be interesting to track the changes that would occur in subsequent generations. More studies are needed on different ethnic groups to determine the most appropriate assessment methods in each group, as well as to identify the impact of generational advancement on body composition.

\section{Acknowledgement}

The authors are grateful to all the subjects and their parents for participating in the study. This study was funded by the Children's Nutrition Research Centre, Department of Paediatrics and Child Health, University of Queensland, Brisbane, Australia.

\section{REFERENCES}

1. Baumgartner R.N. (1996). Electrical impedance and total body electrical conductivity. Human Body Composition (eds. A.F. Roche, S.B. Heymsfield \& T.G. Lohman), pp. 79 - 107. Human Kinetics, Champaign, Illinois, USA.

2. Bell N.A., McClure P.D., Hill R.J. \& Davies P.S.W. (1998). Assessment of foot-to-foot bioelectrical impedance for the prediction of total body water. European Journal of Clinical Nutrition 52: 856 - 859 .

DOI: http://dx.doi.org/10.1038/sj.ejcn.1600661

3. Bland J.M. \& Altman D.G. (1968). Statistical methods for assessing agreement between two methods of clinical measurement. Lancet 1(8476): $307-310$.

4. Deurenberg P., Yap M. \& Van Staveren W.A. (1998). Body mass index and percent body fat: a meta analysis among different ethnic groups. International Journal of Obesity 22: $1164-1171$.

DOI: http://dx.doi.org/10.1038/sj.ijo.0800741

5. Deurenberg P., Deurenberg-Yap M. \& Gurici S. (2002). Asians are different from Caucasians and from each other in their body mass index /body fat percent relationship. Obesity Reviews 3: $141-146$.

DOI: http://dx.doi.org/10.1046/j.1467-789X.2002.00065.x

6. Deurenberg P. \& Deurenberg-Yap M. (2003). Validity of body composition methods across ethnic population groups. Acta Diabetologica 40: S246 - S249. DOI: http://dx.doi.org/10.1007/s00592-003-0077-z

7. Lohman T.G. (1989). Assessment of body composition in children. Pediatric Exercise Science 1: 19-30.

8. McCarthy H.D., Cole T.J., Fry T., Jebb S.A. \& Prentice A.M. (2006). Body fat reference curves for children. International Journal of Obesity 30: $598-602$. DOI: http://dx.doi.org/10.1038/sj.ijo.0803232

9. Whincup R.H., Gilg J.A. \& Papacosta O. (2002). Early evidence of ethnic difference in cardiovascular risk: cross sectional comparison of British South Asian and white children. British Medical Journal 324: 1 - 6.

DOI: http://dx.doi.org/10.1136/bmj.324.7338.635

10. Wickramasinghe V.P., Cleghorn G.J., Edmiston K.A. \& Davies P.S.W. (2005a). Impact of ethnicity upon body composition assessment in Sri Lankan Australian Children. Journal of Paediatrics and Child Health 41(3): $101-106$. DOI: http://dx.doi.org/10.1111/j.1440-1754.2005.00558.x 
11. Wickramasinghe V.P., Cleghorn G.J., Edmiston K.A., Murphy A.J., Abbott R.A. \& Davies P.S.W. (2005b). Ability of bioelectrical impedance to predict percentage fat mass in children of two different ethnic origins. International Journal of Body Composition Research 3(1): 5 - 14.

12. Wickramasinghe V.P., Cleghorn G.J., Edmiston K.A., Murphy A.J., Abbott R.A. \& Davies P.S.W. (2005c). Validity of BMI as a measure of obesity in Australian white Caucasian and Australian Sri Lankan children. Annals of Human Biology 32(1): $60-72$.

DOI: http://dx.doi.org/10.1080/03014460400027805

13. Wickramasinghe V.P., Lamabadusuriya S.P., Cleghorn G.J. \& Davies P.S.W. (2008a). Assessment of body composition in Sri Lankan children: validation of a bioelectrical impedance prediction equation. European Journal of Clinical Nutrition 62(10): 1170 - 1177.

DOI: http://dx.doi.org/10.1038/sj.ejcn.1602835
14. Wickramasinghe V.P., Lamabadusuriya S.P., Cleghorn G.J. \& Davies P.S.W. (2008b). Assessment of body composition in Sri Lankan children: validation of a skin fold thickness equation. Ceylon Medical Journal 53(3): $83-88$.

DOI: http://dx.doi.org/10.4038/cmj.v53i3.247

15. Wickramasinghe V.P., Lamabadusuriya S.P., Cleghorn G.J. \& Davies P.S.W. (2009). BMI as a measure of obesity in Sri Lankan children: validity of currently used cut off values Ceylon Medical Journal 54(4): 114 - 119. DOI: http://dx.doi.org/10.4038/cmj.v54i4.1451

16. Wickramasinghe V.P., Lamabadusuriya S.P., Cleghorn G.J. \& Davies P.S.W. (2012). Development of a segmental bioelectrical impedance prediction equation for the assessment of body composition in Sri Lankan children. International Journal of Body Composition Research 10(3): $79-86$. 